\title{
The Adsorption of Lemon Yellow Dye Using Cationic Cellulose Fibers from Rice Straw as a Sustainable Biosorbent in Aqueous Media
}

\author{
Zhixin Gu, ${ }^{\mathrm{a}, \mathrm{b}}$ Sijia Zhang, ${ }^{\mathrm{a}}$ Chuanqing Zhu, ${ }^{\mathrm{b}}$ and Lijuan Wang ${ }^{\mathrm{a}, *}$ \\ A biosorbent was prepared from the cellulose fibers found in rice straw \\ through cationic modification. The effects of the dosage, $\mathrm{pH}$, contact time, \\ and initial concentration of lemon yellow dye were explored. The static \\ adsorption results showed that cationic modification drastically improved \\ the adsorption capacity of straw cellulose fiber. The maximum equilibrium \\ adsorption capacity value was $137.6 \mathrm{mg} / \mathrm{g}$ and the highest removal \\ reached $99 \%$. The pseudo-second-order kinetic model was a good fit for \\ the adsorption process, together with the Langmuir isotherm model. The \\ adsorption reaction was spontaneous, and the adsorption process was an \\ exothermic reaction, which was shown by the thermodynamic model. As \\ the adsorption time became longer, the effluent concentration became \\ larger until reaching equilibrium. The time was $420 \mathrm{~min}$. After desorption \\ using a dilute $\mathrm{NaOH}$ solution, the maximum adsorption capacity was still \\ $36.1 \mathrm{mg} / \mathrm{g}$ and the maximum removal still reached $36.2 \%$. The parameters \\ calculated from the Yoon-Nelson model have a good fit with the \\ experimental data. In short, cationic straw cellulose fiber is an effective \\ and easy to prepare biosorbent. This work offers a new method for dye \\ wastewater purification and solves the effective utilization of rice straw \\ resources.
}

Keywords: Rice straw; Cationic; Cellulose fiber; Lemon yellow dye; Adsorption

Contact information: a: Key Laboratory of Bio-based Materials Science and Technology of Ministry of Education, Northeast Forestry University, Harbin 150040 PR China; b: College of Information and Computer Engineering, Northeast Forestry University, Harbin 150040 PR China;

*Corresponding author: donglinwlj@163.com

\section{INTRODUCTION}

Dye is widely used in many fields, but it easily pollutes the environment (Baldikova et al. 2015). The characteristics of dye wastewater has a complex composition, deep color, high toxicity, strong acidity, and high COD content, and has always been a problem in terms of environmental protection (Heibati et al. 2015; Zhang et al. 2017).

There are three common treatment methods for dye-polluted water: physical, chemical, and biosorption (Elumalai et al. 2016; Asfaram et al. 2017). Each method has its own advantages and disadvantages. Electrochemical methods have different decolorization effects on different dyes (De et al. 2018). However, they are highly efficient in avoiding secondary pollution (Alver et al. 2017). The follow-up treatment is simple, but its cost and energy consumption are high. The advantages of the biological method include high purification efficiency, low price, and no secondary damage to water. However, the decolorization rate and COD removal are not high (Sun et al. 2016). The adsorption method is a physical method that is simple to use and yields a strong purification effect, etc. However, the adsorbent has a high cost and often cannot be reused (Patil et al. 2015). 
Moreover, improper subsequent treatment may cause secondary pollution. To date, the adsorption property of activated carbon is widely used to treat dye wastewater. It has a porous structure, high specific surface area, and high absorptivity (Ge et al. 2016; Ciftci et al. 2018). However, its disadvantages are it is difficult to regenerate, has a high cost, and the possibility of recycling is low (Sudhan et al. 2016). However, biosorbents can make up for the disadvantages of activated carbon adsorption.

It is estimated that China produces 300 million tons of rice straw a year (Zhu et al. 2017). A primary use of rice straw involves its crushing in the field for the preparation coal-based fuel for heating. However, a large part of it is still directly incinerated, which not only wastes resources but also seriously pollutes the environment (Fan et al. 2017; Zazycki et al. 2017). The primary components of rice straw are cellulose (43.2\%), hemicellulose (11.5\%), and lignin (28.9\%). Rice straw is rich in hydroxyl groups, aldehyde groups, and carboxyl groups, as well as other active groups, which can undergo a variety of chemical modification reactions (Chen et al. 2019). Recently, using rice straw as a biosorbent to adsorb dye wastewater has been a popular research topic.

From this perspective, many studies have made a lot of progress. A solid adsorbent used for $\mathrm{SO}_{2}$ adsorption was prepared from magnesium salt/rice straw via co-precipitation/ calcination (Hosseini et al. 2018). Xia et al. (2013) used rape straw to extract natural cellulose and prepared several adsorbents for organic dye wastewater treatment with good results. Xie et al. (2019) prepared a wheat straw cellulose/GO composite material for the removal of $\mathrm{Cd}^{2+}$ and $\mathrm{Pb}^{2+}$ from water and the removal reached 93.25\%. Halysh et al. (2020) determined the adsorption capacity for methylene blue $(68.8 \mathrm{mg} / \mathrm{g})$ using a lignocellulosic sorbent derived from sugar cane straw. Fiber biosorbents have a low-cost and abundant; the problem is their low adsorption capacity and as such, it needs modification to improve its adsorption capacity.

$\mathrm{Hu}$ et al. (2016) used cationic flax noil cellulose as an adsorbent to remove ciprofloxacin from an aqueous solution and confirmed that the cationic groups had been successfully bound to the cellulose molecules after functionalization. Li et al. (2019) showed that $\mathrm{KMnO}_{4}$-modified rice husk can be used as an effective alternative adsorbent for the removal of malachite green (MG) from wastewater, with an adsorption rate greater than $90 \%$. Ghasemi et al. (2020) used modified barley straw to remove MG from industrial wastewater. The removal efficiency of MG increased as the modified barley straw dosage, $\mathrm{pH}$, and contact time were increased (Ghasemi et al. 2020). Hu et al. (2019) developed wheat straw modified with maleated rosin to improve its adsorption capacity for methylene blue (MB) dyes, with an adsorption capacity of $113.3 \mathrm{mg} / \mathrm{g}$. Lima et al. (2018) studied MG adsorption by raw and modified corn straw (MCS) and the adsorbed quantity at saturation ranged from $164.2 \mathrm{mg} / \mathrm{g}$ to $528.2 \mathrm{mg} / \mathrm{g}$.

All the above studies focused on the static adsorption characteristics of modified cellulose adsorbents prepared from straw. These adsorbents had a low adsorption capacity. Very few studies have been done on the application of modified straw cellulose in dye treatment, especially in terms of the dynamic adsorption performance, which can describe the practical application more intuitively and provide data for industrial design. In order to further improve the adsorption capacity, rice straw was modified via cationization to prepare cationic straw cellulose fiber (CSCF), which could purify anionic dye solutions. On the basis of studying the static adsorption, this work studied the dynamic adsorption characteristics of lemon yellow (LY) dye using CSCF. It is mainly used for coloring food, beverage, medicine, cosmetics and wool. Lemon yellow wastewater has deep chroma and high COD content, which is one of the difficulties in dye wastewater treatment. The Yoon- 
Nelson model was used to simulate the dynamic adsorption behavior to provide basic data for industrial applications. This cheap and efficient biomass material will bring new economic and social benefits to dye wastewater treatment.

\section{EXPERIMENTAL}

\section{Materials}

Caustic soda SCF was prepared in the laboratory. The sodium hypochlorite $(\mathrm{NaClO}, 120 \mathrm{~g} / \mathrm{L})$ and hydrochloric acid $(\mathrm{HCl}, 36 \%)$ was purchased from Shanghai Shenmei Pharmaceutical Technology Co., Ltd. (Shanghai, China). The sodium hydroxide $(\mathrm{NaOH})$, triethylamine $\left(\mathrm{C}_{6} \mathrm{H}_{15} \mathrm{~N}\right)$, epichlorohydrin $\left(\mathrm{C}_{3} \mathrm{H}_{5} \mathrm{ClO}\right)$, anhydrous ethanol $\left(\mathrm{C}_{2} \mathrm{H}_{5} \mathrm{OH}\right)$, and $\mathrm{LY}\left(\mathrm{C}_{16} \mathrm{H}_{9} \mathrm{~N}_{4} \mathrm{Na}_{3} \mathrm{O}_{9} \mathrm{~S}_{2}\right)$ were analytical reagent grade purchased from Yongda chemical Reagent Co. Ltd (Tianjin, China).

\section{Preparation of the Cationic Straw Cellulose Fiber (CSCF)}

In order to be able to remove anionic substances from solution, the SCF was cationized. The $\mathrm{NaClO}$ solution was well mixed with SCF and stirred at a temperature of $35{ }^{\circ} \mathrm{C}$ for $1 \mathrm{~h}$ at a constant temperature via a constant speed agitator (JJ-1B). The moisture was filtered out, and the material was rinsed to remove the residual $\mathrm{NaClO}$. The SCF before and after bleaching is shown in Figs. 1a and 1b. The SCF with an 80 mesh to 120 mesh size was selected using an electric vibrating screen (8411), as shown in Fig. 1c. The qualified SCF and $\mathrm{NaOH}$ solution (20\%) were added to a beaker and stirred via a water bath thermostatic oscillator (DSHZ-300A). A triethylamine ethanol solution with a volume fraction of $34 \%$ was added into the flask, which was stirred at a temperature of $80{ }^{\circ} \mathrm{C}$ for 3 $\mathrm{h}$. The resulting solution was filtered and rinsed to remove the residual triethylamine. Finally, the CSCF was put into a vacuum drying oven (DZ-2AII) at a temperature of 60 ${ }^{\circ} \mathrm{C}$, as shown in Fig. 1d.

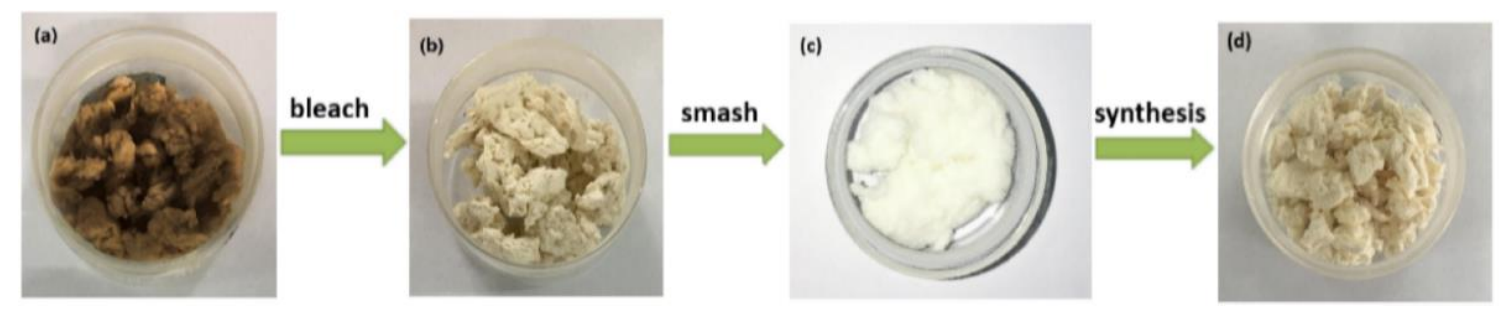

Fig. 1. CSCF preparation process

\section{Characterization of the Cationic Straw Cellulose Fiber (CSCF)}

The morphology of samples was examined via a Quanta 200 scanning electron microscope (Philips-FEI Co., AMS, Netherlands), with an accelerating voltage of $20 \mathrm{kV}$. The morphology of the CSCF was observed using a JEM-2100 transmission electron microscope (TEM).

\section{Adsorption Process}

The effects of the adsorbent dosage, $\mathrm{pH}$, contact time, and initial concentration of LY dye on the CSCF adsorption were studied. Different amounts of CSCF adsorbent and contact time were demonstrated at various time intervals (10 min to $180 \mathrm{~min}$ ). The CSCF 
adsorbent and LY dye solution were added into a conical flask at various initial LY dye concentrations $(20 \mathrm{mg} / \mathrm{L}, 40 \mathrm{mg} / \mathrm{L}, 60 \mathrm{mg} / \mathrm{L}, 80 \mathrm{mg} / \mathrm{L}$, and $100 \mathrm{mg} / \mathrm{L})$. The solution was shaken at temperatures of $30{ }^{\circ} \mathrm{C}, 40{ }^{\circ} \mathrm{C}$, and $50{ }^{\circ} \mathrm{C}$ and at $\mathrm{pH}$ values of $2,4,6,8,10$, and 12. After filtration, the absorbance was measured, and the concentration of the residual dye after adsorption $\left(C_{e}\right)$ was calculated from the standard curve. The adsorption capacity $(Q)$ and removal rate $(\omega)$ were calculated using Eqs. 1 and 2,

$$
\begin{aligned}
& Q=\frac{\left(C_{o}-C_{e}\right) \times V_{o}}{m} \\
& \omega=\frac{\left(C_{o}-C_{e}\right) \times 100 \%}{C_{o}}
\end{aligned}
$$

where $m$ is the mass of the adsorbent $(\mathrm{mg}), V_{o}$ is the volume of solution (mL), and $C_{o}$ and $C_{e}$ are the initial and final equilibrium concentrations $(\mathrm{mg} / \mathrm{L})$.

\section{Dynamic Adsorption}

The CSCF adsorbent ( $0.9 \mathrm{~g}$ ) was put into a column (the column diameter was 3.0 $\mathrm{cm}$ and the column height was $11.5 \mathrm{~cm}$ ) as the stationary phase, and the adsorption bed height was $2.0 \mathrm{~cm}$ (Fig. 2a). The flow rate of the LY solution $(45 \mathrm{mg} / \mathrm{L}$ and $50 \mathrm{mg} / \mathrm{L}$ ) was $5 \mathrm{~mL} / \mathrm{min}$, and the effluent solution was collected. The absorbance of the filtrate was measured for each $5 \mathrm{~mL}$ solution (Fig. 2b).
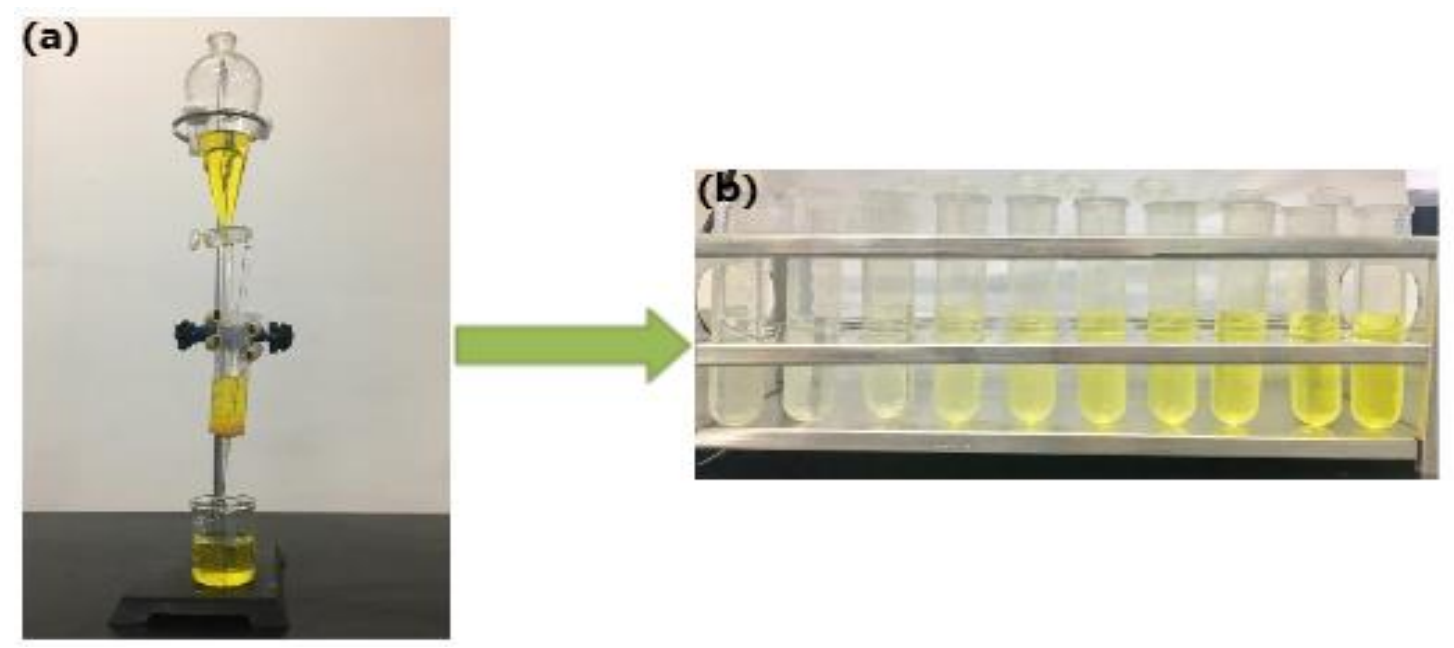

Fig. 2. Dynamic adsorption process

\section{Desorption and Secondary Adsorption}

The CSCF after undergoing saturation adsorption (Fig. 3a) and the $\mathrm{NaOH}$ solution $(0.1 \mathrm{~mol} / \mathrm{L})$ were added into conical flasks. Desorption was conducted by shaking at a temperature of $30^{\circ} \mathrm{C}$ for $5 \mathrm{~min}$ to $50 \mathrm{~min}$. The CSCF after filtering and desorption is shown in Fig. 3b. The absorbance of the filtrates were measured, respectively. The solution concentration after desorption and the desorption rate of the CSCF after saturated adsorption were calculated. The CSCF adsorbent after desorption and the LY dye solution $(50 \mathrm{mg} / \mathrm{L})$ were added into the conical flask. After shaking and filtration, the secondary adsorption of LY dye occurred (Fig. 3c) and the $C_{e}, Q$, and $\omega$ after the desorption occurred were calculated. 


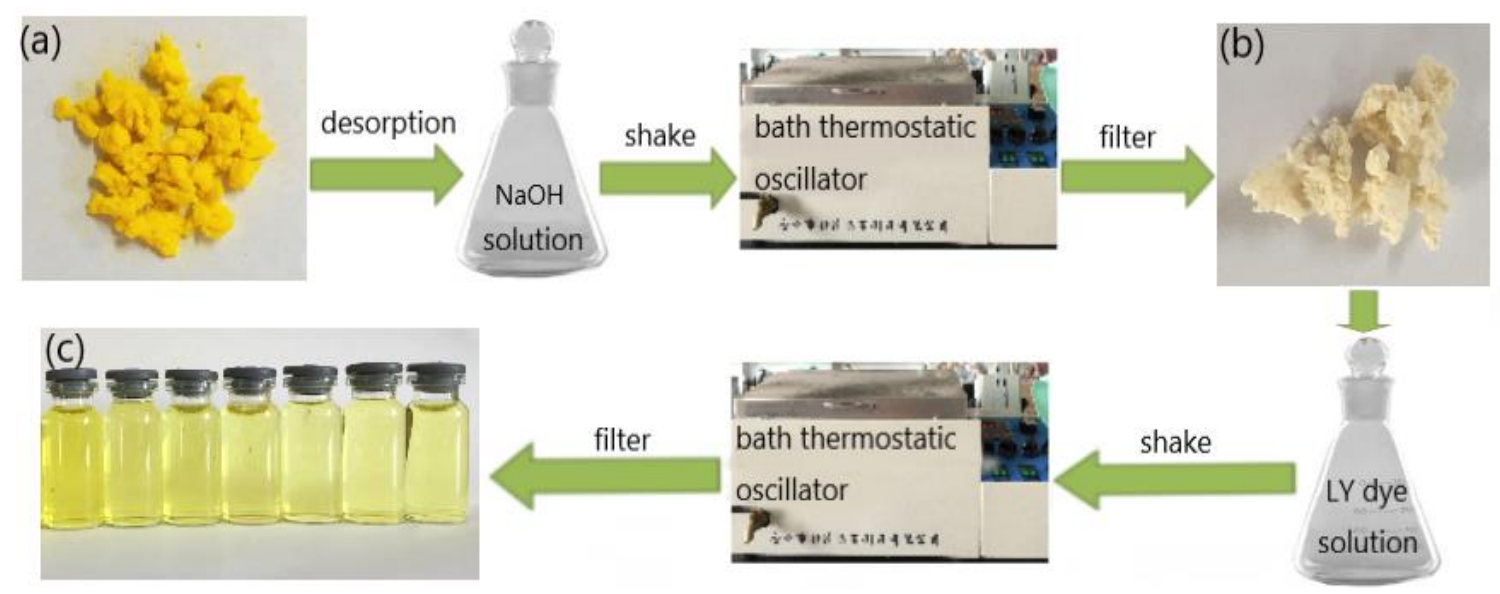

Fig. 3. Desorption and secondary adsorption

\section{RESULTS AND DISCUSSION}

\section{Scanning Electron Microscopy (SEM) Analysis}

The SEM images of the SCF and CSCF are shown in Figs. $4 a$ and $4 b$. The surface morphology of the SCF and CSCF had obviously changed. The SCF was filamentous, with many large gullies on the surface and a small amount of impurities. The surface of the CSCF had fewer impurities and was fully saturated. There were some tiny gullies on the surface and some relatively small pore structures of different sizes. These changes visible in the SEM images suggest an increase in surface area, which would be favorable for adsorption interactions.

\section{Fourier-Transform Infrared Spectroscopy (FTIR) and X-Ray Diffraction (XRD) Analysis}

The FTIR spectra of the SCF and CSCF are shown in Fig. 4c. The absorption peak of SCF at $3330 \mathrm{~cm}^{-1}$ is the vibration absorption peak of $\mathrm{O}-\mathrm{H}$. The telescopic vibration peak of $\mathrm{C}-\mathrm{H}$ in $-\mathrm{CH}_{2}-$ occurs at $2900 \mathrm{~cm}^{-1}$. The telescopic vibration peak of $\mathrm{C}=\mathrm{O}$ occurs at 1743 $\mathrm{cm}^{-1}$. The lactone and $\mathrm{O}-\mathrm{H}$ in-plane bending vibration peak occurs at $1316 \mathrm{~cm}^{-1}$. The peak at $1028 \mathrm{~cm}^{-1}$ represents the telescopic vibration peak of the cellulose skeleton. The spectrum of CSCF shows that the strength of the telescopic vibration peak of $\mathrm{O}-\mathrm{H}$ is obviously weakened and deviates towards a high wave number. The strength of the absorption peak of $\mathrm{C}-\mathrm{H}$ in $-\mathrm{CH}_{2}-$ is slightly enhanced, which showed that the new $\mathrm{CH}_{2}{ }^{-}$ group was successfully introduced into the SCF molecules. The telescopic vibration peak of C-N is shown at $1470 \mathrm{~cm}^{-1}$, and the CSCF spectra had less miscellaneous peaks than the $\mathrm{SCF}$ spectra. These findings demonstrate that the quaternary ammonium group molecular structure was successfully introduced into the molecular structure of SCF, which indicated that the CSCF was indeed synthesized.

As can be seen from Fig. $4 d$, the characteristic peaks at $15.52^{\circ}$ and $22.32^{\circ}$ show that SCF was a typical cellulose I-type structure. There was only one characteristic peak at $20.26^{\circ}$. After cationic modification, the intermolecular and intramolecular hydrogen bonds of SCF were destroyed, which resulted in a change of crystal shape. 

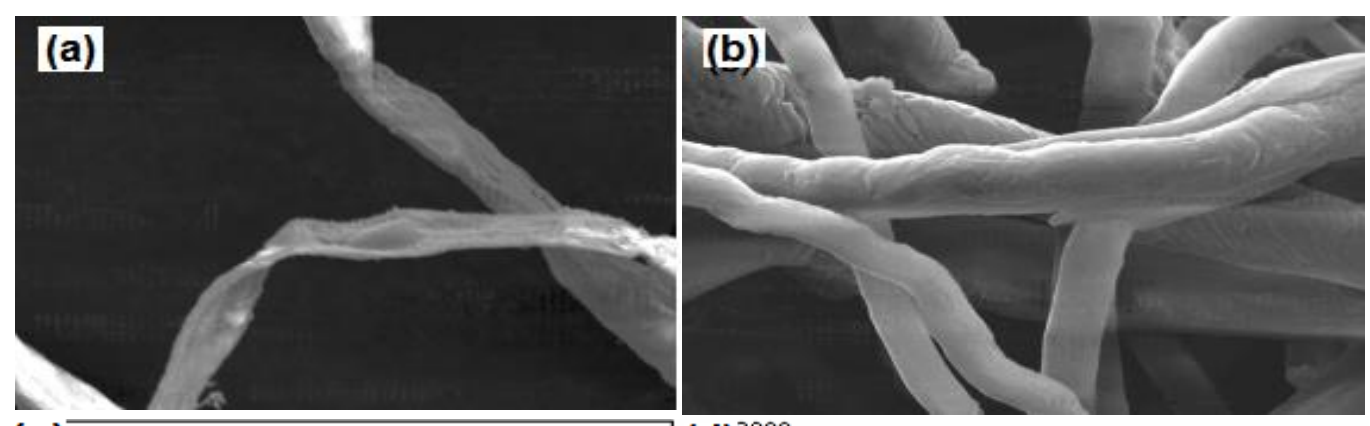

(c)

(a) straw cellulose

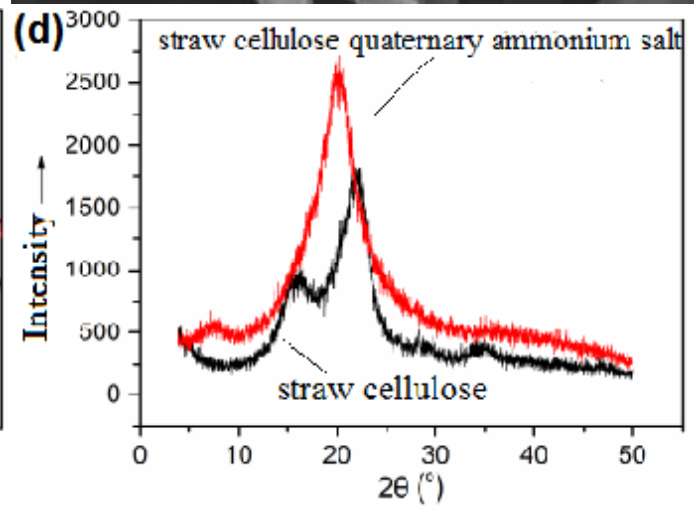

(b) quaternary ammonium salt

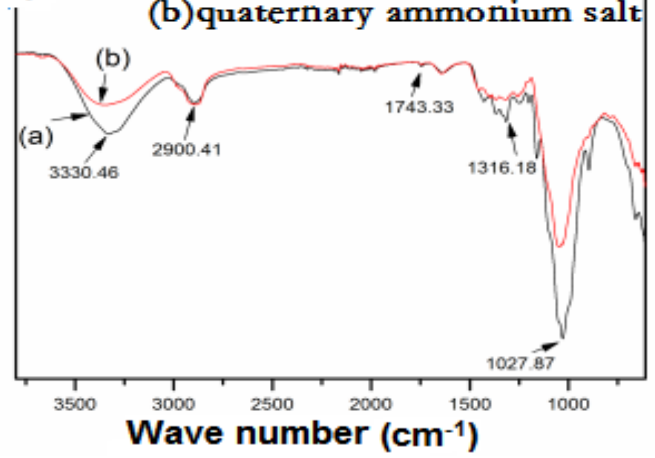

Fig. 4. Characterization images of the SCF and CSCF

\section{Purification Performance}

As shown in Figs. 5a and 5b, the adsorption capacity for LY dye was able to reach $138 \mathrm{mg} / \mathrm{g}$, and it gradually decreased as the CSCF dosage was increased. The percentage of removal gradually increased until the system reached equilibrium, with a maximum of 99.3\%. The optimal CSCF dosage is $0.05 \mathrm{~g}$.

Rapid adsorption occurred within $30 \mathrm{~min}$, whereas the period of 30 to $90 \mathrm{~min}$ was characterized by slow adsorption, as shown in Figs. 5c and 5d. After 90 min, the system reached equilibrium adsorption. The optimal adsorption time was judged to be $90 \mathrm{~min}$, the highest adsorption capacity was $84.0 \mathrm{mg} / \mathrm{g}$, and the maximum removal was $84.3 \%$. As the temperature increased, the adsorption capacity and removal rate decreased at the same contact time, which indicated an exothermic reaction.

The maximum adsorption capacity was $94.0 \mathrm{mg} / \mathrm{g}$, as shown in Figs. 5e and 5f. The optimal initial concentration was judged to be $50 \mathrm{mg} / \mathrm{L}$. The removal percentage was $96.4 \%$ at its highest. The increase of the initial concentration not only increases the probability of collision between dye molecules and the adsorbent, but it also increases the concentration difference between the surface of the adsorbent and the main body of the solution. 

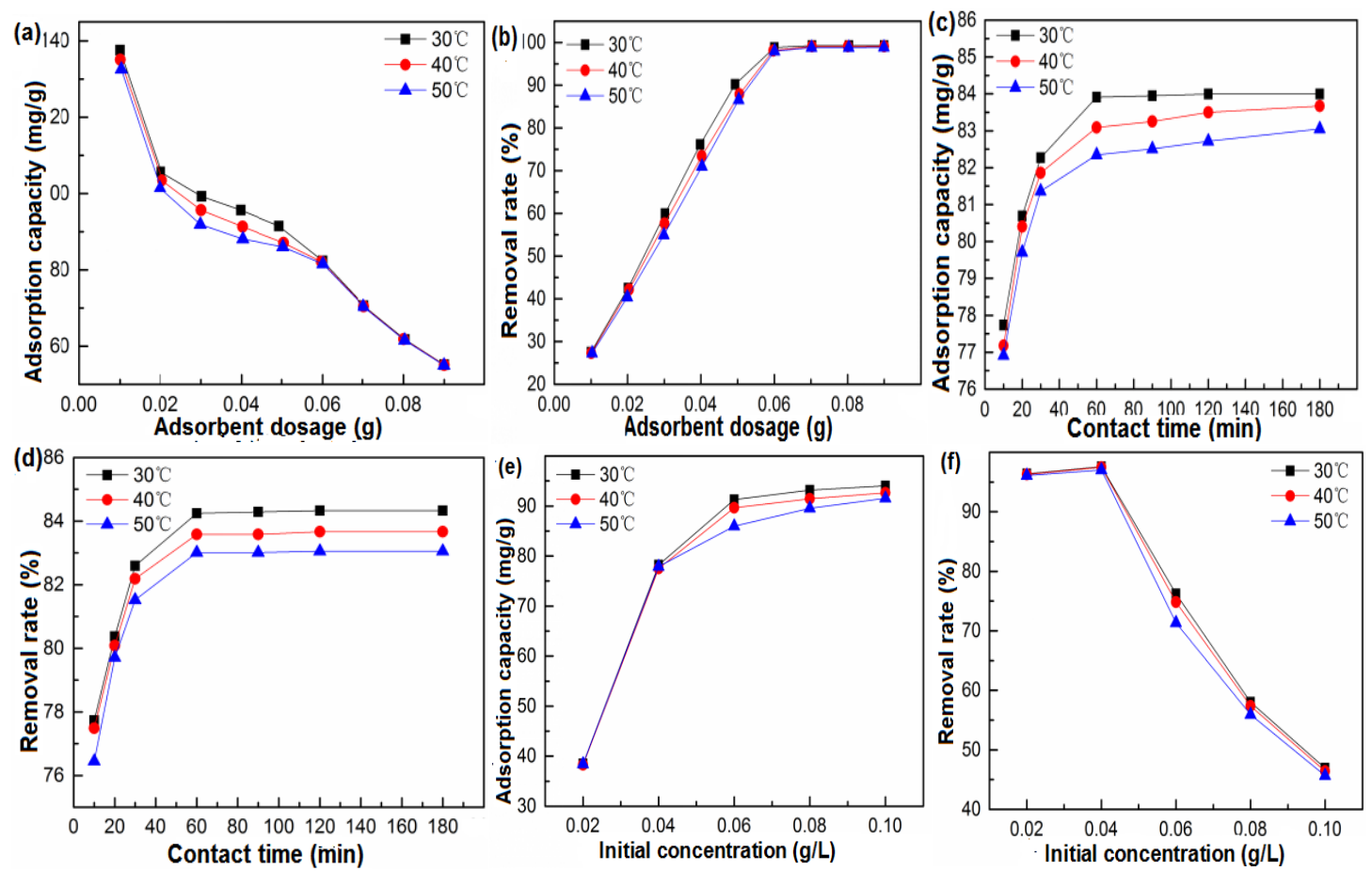

Fig. 5. Purification performance

As shown in Fig. 6, the $\mathrm{pH}$ had a strong influence on the adsorption of LY dye solution by CSCF. When the LY dye has an optimal $\mathrm{pH}$ of 4 , the adsorption capacity and removal rate can reach $88.7 \mathrm{mg} / \mathrm{g}$ and $88.7 \%$, respectively.

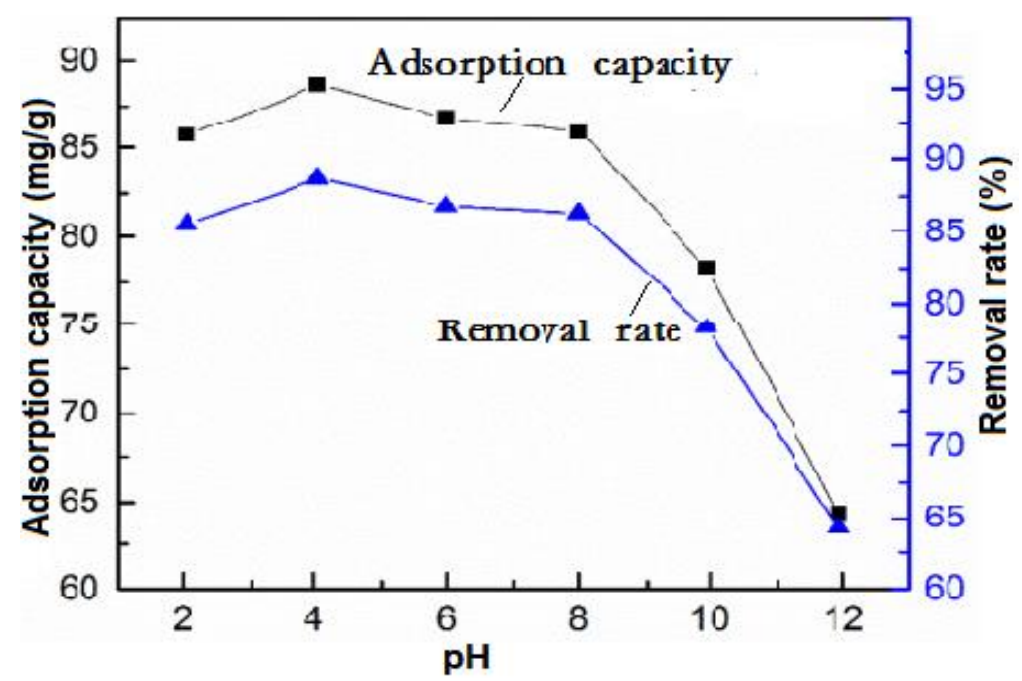

Fig. 6. Effects of different $\mathrm{pH}$ values on the purification performance 


\section{Adsorption Kinetics}

Adsorption kinetics studies the relationship between the adsorption capacity and the contact time, i.e., the adsorption rate and the dynamic equilibrium of adsorption.

\section{Pseudo-first-order kinetic model}

Assuming that the adsorption is mainly affected by diffusion, it can be calculated according to Eq. 3,

$$
\ln \left(q_{e}-q_{t}\right)=\ln q_{e}-k_{1}
$$

where $k_{1}$ is the rate constant $\left(\mathrm{min}^{-1}\right), q_{e}$ and $q_{t}$ are the adsorption capacity at equilibrium and at time $t(\mathrm{mg} / \mathrm{g})$. The conclusion is that the adsorption rate is proportional to $q_{e}$ minus $q_{t}$.

According to the experiment data, the relationship between $\ln \left(q_{e}-q_{t}\right)$ and $t$ at different times is shown in Fig. 7a. The constants and adsorption capacity were calculated using the slope and intercept of the line.

\section{Pseudo-second-order kinetic model}

The expression of the pseudo-second-order kinetic model is shown in Eq. 4,

$$
\frac{t}{q_{t}}=\frac{1}{k_{2} q_{e}^{2}}+\frac{1}{q_{e}} t
$$

where $k_{2}$ is the rate constant $\left(\mathrm{min}^{-1}\right)$.

According to the experiment data, the relationship between $t / q_{e}$ and $t$ at different times is shown in Fig. 7b. The rate constant and adsorption capacity were calculated using the slope $\left(1 / q_{e}\right)$ and intercept $\left(1 / k_{2} q_{e}{ }^{2}\right)$ of the line.
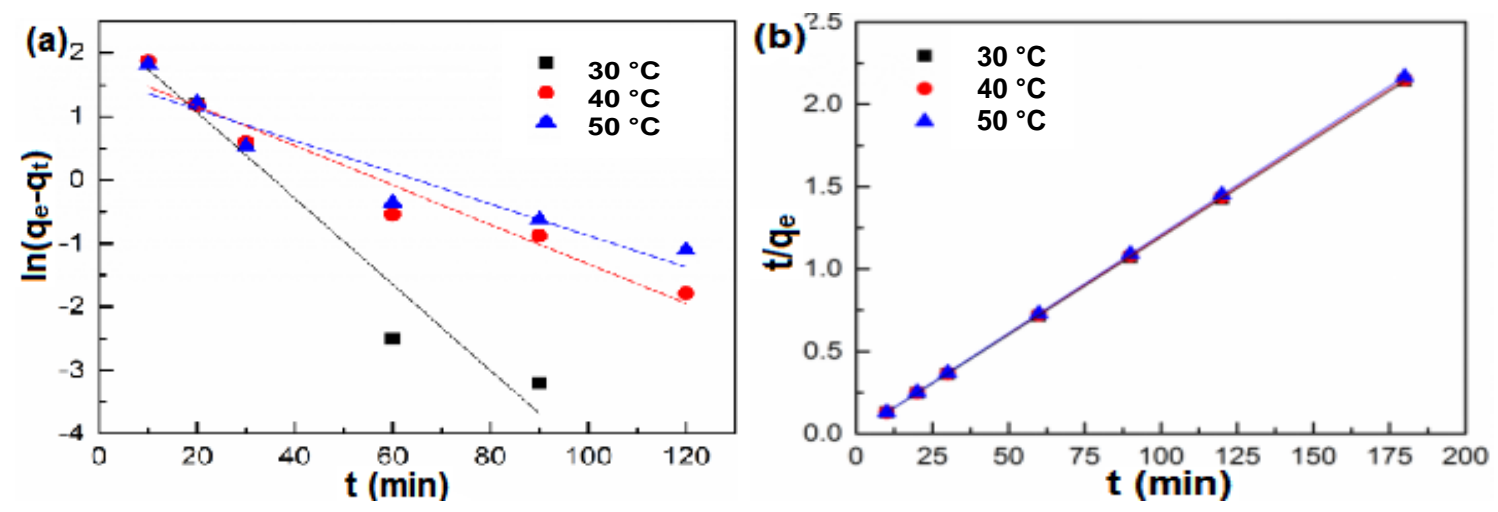

Fig. 7. Adsorption kinetics of adsorption reaction

Table 1. Related Parameters of the Adsorption Kinetics

\begin{tabular}{|c|c|c|c|c|c|c|}
\hline & \multicolumn{3}{|c|}{ Pseudo-First-Order } & \multicolumn{3}{c|}{ Pseudo-Second-Order } \\
\hline$\theta^{\circ} \mathrm{C}$ & $k_{1}\left(\mathrm{~min}^{-1}\right)$ & $q_{e}(\mathrm{mg} / \mathrm{g})$ & $\mathrm{R}^{2}$ & $k_{2 \times 10^{-2}\left(\mathrm{~min}^{-1}\right)}$ & $q_{e}(\mathrm{mg} / \mathrm{g})$ & $\mathrm{R}^{2}$ \\
\hline 30 & 0.0311 & 5.9352 & 0.9494 & 1.619 & 84.7458 & 1.0000 \\
\hline 40 & 1.402 & 11.2639 & 0.9510 & 1.402 & 84.0336 & 1.0000 \\
\hline 50 & 0.3050 & 5.0048 & 0.9021 & 1.398 & 83.3333 & 1.0000 \\
\hline
\end{tabular}

The adsorption kinetics parameters are shown in Table 1. There was a linear relationship between $\ln \left(q_{e}-q_{t}\right)$ and $t$ (as shown in Fig. 7a and Fig. 7b). The reaction rate was approximately linear with the concentration of LY dye. 
Comparing the results of the two models, the pseudo-second-order kinetic model better described the adsorption process. The linear fit of the experimental data presented a more linear form with $\mathrm{R}^{2}$ equal to 1 . The theoretical adsorption capacity was closer to the actual adsorption capacity. Such fits of data to the pseudo-second-order kinetic model support diffusion as the rate-determining step (Hubbe et al. 2019).

\section{Adsorption Isotherm}

An adsorption isotherm refers to the relationship between the amount of adsorbates attached on the surface of an adsorbent and that in the solution at adsorption equilibrium. It can describe the adsorption process and make it possible to infer the interaction between adsorbents and adsorbents.

\section{Langmuir isotherm}

The expression of the Langmuir isotherm is shown in Eq. 5,

$$
\frac{C e}{q_{e}}=\frac{1}{K_{L} q_{m}}+\frac{1}{q_{m}} C e
$$

where $C_{e}$ is the solution concentration at equilibrium $(\mathrm{mg} / \mathrm{L}), q_{e}$ is the adsorption capacity at equilibrium $(\mathrm{mg} / \mathrm{g}), q_{m}$ is the maximum monolayer adsorption capacity $(\mathrm{mg} / \mathrm{g})$, and $K_{L}$ is the Langmuir adsorption constant related to binding (L/mg) (Langmuir 1916).

The relationship between $C_{e} / q_{e}$ and $C_{e}$ at different adsorbent dosages is shown in Fig. 8a. The $q_{e}, K_{L}$, and $q_{m}$ were calculated using the slope and intercept of the fit line of the Langmuir isotherm equation. The linear fit of the experimental data showed a linear form, and $\mathrm{R}^{2}$ was close to 1.0 .

\section{Freundlich isotherm}

This isotherm, based on an empirical equation, makes it possible to assume that the adsorption occurs on a heterogeneous surface at nonidentical sites with different energies of adsorption that are not always available (Freundlich 1906).

$$
\ln q e=\ln K f+\frac{1}{n} \ln C e
$$

In Eq. $6, K_{f}(\mathrm{~L} / \mathrm{g})$ and $n$ are the Freundlich constants relative to the adsorption capacity and intensity of adsorption.

According to the experimental data, the relationship between $\ln q_{e}$ and $\ln C_{e}$ at different CSCF dosages was found. The fit line of the Freundlich isotherm equation is shown in Fig. 8b. The $K_{f}$ and $n$ values were calculated using the slope and intercept of the line, and the parameter data were calculated (Table 2).

Figure $8 \mathrm{~b}$ shows there was no linear relationship between the $\log q_{e}$ and $\log C_{e}$ of the Freundlich isothermal adsorption model. There was a good linear relationship between the $C_{e} / q_{e}$ and $C_{e}$. The maximum of $\mathrm{R}_{2}$ was greater than 0.95 . The theoretical adsorption capacity was close to the actual adsorption capacity. 

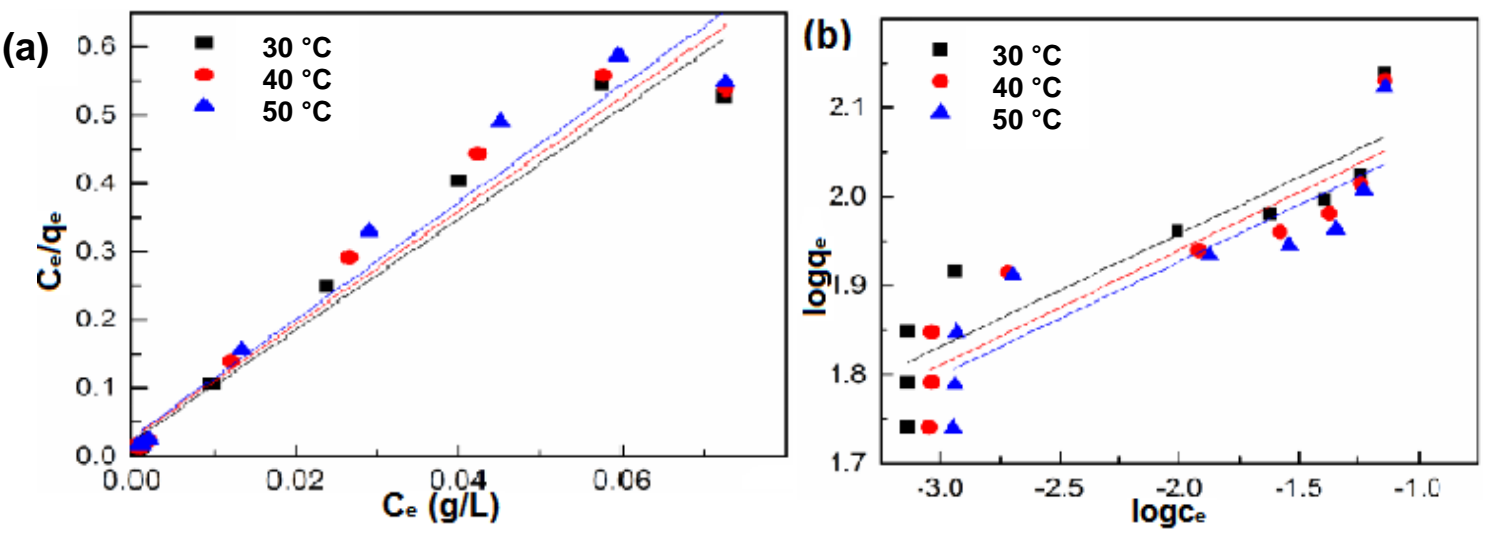

Fig. 8. Isothermal equation fitting

Table 2. Related Parameters of the Isotherms

\begin{tabular}{|c|c|c|c|c|c|c|}
\hline & \multicolumn{3}{|c|}{ Langmuir } & \multicolumn{3}{c|}{ Freundlich } \\
\hline $\begin{array}{c}{ }^{\circ} \mathrm{C} \\
{ }^{2}\end{array}$ & $K_{L}(\mathrm{~L} / \mathrm{mg})$ & $Q_{m}(\mathrm{mg} / \mathrm{g})$ & $\mathrm{R}^{2}$ & $K_{f}(\mathrm{~L} / \mathrm{g})$ & $n$ & $\mathrm{R}^{2}$ \\
\hline 30 & 1.1670 & 104.500 & 0.9980 & 9.1349 & 7.8740 & 0.8285 \\
\hline 40 & 0.3182 & 119.964 & 0.9572 & 9.0151 & 7.7220 & 0.8190 \\
\hline 50 & 0.3050 & 116.260 & 0.9524 & 8.8640 & 7.8370 & 0.7808 \\
\hline
\end{tabular}

\section{Thermodynamic Model}

In order to test the adsorption capacity of the CSCF adsorbent for LY dye, the thermodynamic parameters were introduced, i.e., $\Delta G^{0}, \Delta H^{0}$, and $\Delta S^{0}$. They were studied using the experimental data detailing the effects of the temperature.

The expression of the change of Gibbs free energy $\Delta G^{0}(\mathrm{~kJ} / \mathrm{mol})$, the enthalpy change $\Delta H^{0}(\mathrm{~kJ} / \mathrm{mol})$, and entropy change $\Delta S^{0}(\mathrm{~J} / \mathrm{mol})$ are shown in Eqs. 7, 8, and 9, respectively,

$$
\begin{aligned}
& K_{d}=\frac{q_{e}}{C_{e}} \\
& \Delta G^{0}=-R T \ln \left(K_{d}\right) \\
& \ln \left(K_{d}\right)=\Delta S^{0} / R-\Delta H^{0} / R T
\end{aligned}
$$

where $K_{d}$ is the distribution coefficient, $q_{e}$ is the adsorption capacity at equilibrium $(\mathrm{mg} / \mathrm{g})$, $C_{e}$ is the solution concentration at equilibrium $(\mathrm{mg} / \mathrm{L})$, and $R$ is the gas constant $(\mathrm{J} / \mathrm{mol} \cdot \mathrm{K})$ (Chen et al. 2019).

The experimental data of the different desorption times were put into Eq. 8 to obtain the $\Delta G^{0}$. The relation line of $\ln K_{d} \sim 1 / T$ was plotted as shown in Fig. 9. Based on the slope and intercept of the line, $\Delta H^{0}$ and $\Delta S^{0}$ were calculated. 


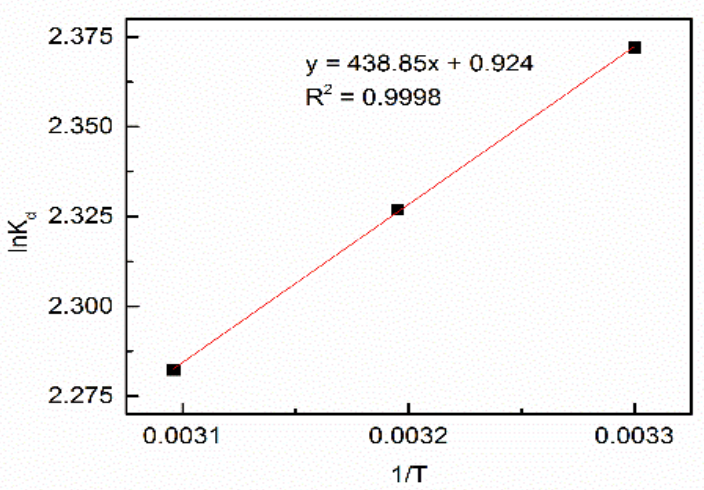

Fig. 9. The relation of $\operatorname{lnKd} \sim 1 / T$

Table 3. Thermodynamic Parameters

\begin{tabular}{|c|c|c|c|c|}
\hline \multirow{2}{*}{$\Delta H^{0}(\mathrm{~kJ} / \mathrm{mol})$} & \multirow{2}{*}{$\Delta S^{0}(\mathrm{~J} / \mathrm{mol})$} & \multicolumn{3}{|c|}{$\Delta G^{0}(\mathrm{~kJ} / \mathrm{mol})$} \\
\cline { 3 - 5 } & & $30^{\circ} \mathrm{C}$ & $40^{\circ} \mathrm{C}$ & $50^{\circ} \mathrm{C}$ \\
\hline-3.6486 & 7.6821 & -5.9754 & -6.0553 & -6.1290 \\
\hline
\end{tabular}

The $\Delta G^{0}$ was negative in the adsorption process (as shown in Table 3), which implies that the adsorption reaction was spontaneous. The $\Delta H^{0}$ was less than 0 , so the adsorption process was an exothermic reaction. An increase in temperature would be unfavorable to the adsorption process.

\section{The Analysis of Dynamic Adsorption}

This analysis assumes that the probability of the decreasing adsorption rate is proportional to the probability of the adsorbate adsorption and adsorbent penetration.

The Yoon-Nelson model is simpler than other dynamic models. It does not need detailed data on the properties of the adsorbents, e.g., the adsorbent, adsorbate, and fixed bed properties, so, the calculation process is simplified. This model is shown in Eqs. 10 and 11,

$$
\begin{aligned}
& \frac{C_{e}}{C_{o}}=\frac{1}{1+\exp [k(\tau-t)]} \\
& \ln \frac{C_{e}}{C_{o}-C_{e}}=k t-k \tau
\end{aligned}
$$

where $\tau$ is the time taken for $50 \%$ of the adsorbate to be adsorbed $(\mathrm{min}), k$ is the rate constant $\left(\mathrm{min}^{-1}\right), C_{o}$ is the initial concentration of the adsorbate $(\mathrm{mg} / \mathrm{L})$, and $C_{e}$ is the outflow concentration of the adsorbate $(\mathrm{mg} / \mathrm{L})$.

A line can be obtained by plotting $t$ in terms of $\ln \left(C_{e} /\left(C_{o}-C_{e}\right)\right)$. Using the slope and intercept of the line, $k$ and $\tau$ were calculated.

The linear form of Yoon-Nelson model is shown as Eqs. 12 and 13,

$$
\begin{aligned}
& t=\tau+\frac{1}{k} \ln \frac{C_{e}}{C_{o}-C_{e}} \\
& q_{o}=\frac{1}{2} C_{o} \theta(2 \tau) / m=C_{o} \theta \tau / m
\end{aligned}
$$

where $q_{o}$ is the mass of the adsorbate adsorbed per unit mass of adsorbent at a given flow rate $(\mathrm{mg} / \mathrm{g}), m$ is the mass of the adsorbent in the column $(\mathrm{g})$, and $\theta$ is the effluent rate of the adsorbent (L/min) (Enniya et al. 2018). 
Table 4. Yoon-Nelson Model Parameters

\begin{tabular}{|c|c|c|c|c|}
\hline$C_{o}(\mathrm{mg} / \mathrm{L})$ & $k \times 10^{3}(1 / \mathrm{min})$ & $q_{\circ}(\mathrm{mg} / \mathrm{g})$ & $T(\mathrm{~min})$ & $\mathrm{R}^{2}$ \\
\hline 45.33 & 0.01 & 28.761 & 421 & 0.9536 \\
\hline 51.53 & 0.02 & 13.157 & 360 & 0.9385 \\
\hline
\end{tabular}
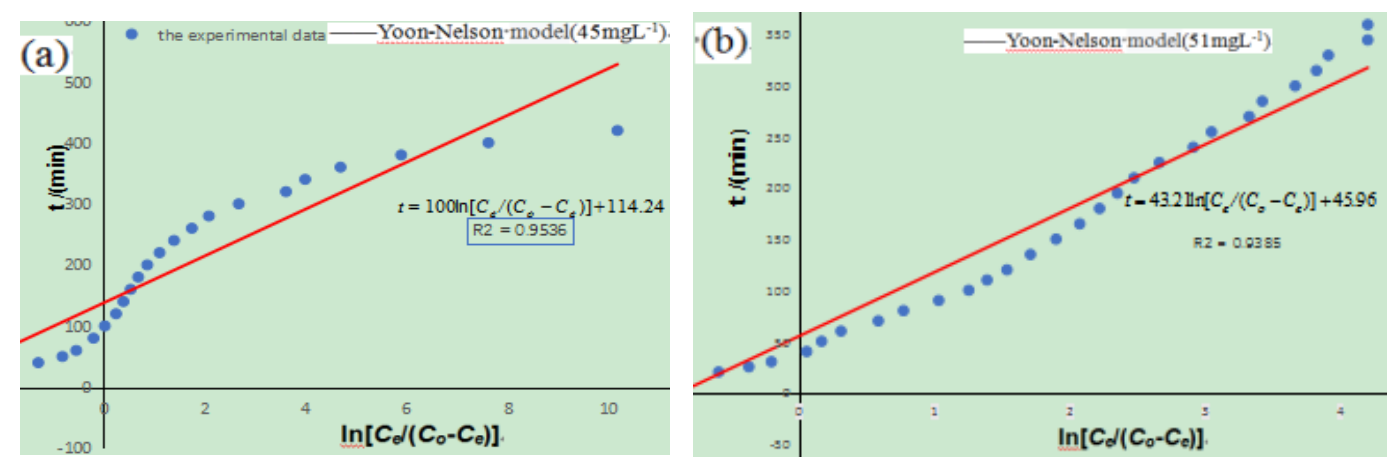

Fig. 10. Yoon-Nelson model

The Yoon-Nelson model dynamic adsorption parameters of the CSCF adsorbent for LY dye are shown in Table 4. When the concentration of the LY dye solution was 45 $\mathrm{mg} / \mathrm{L}$, the calculated theoretical data was a good fit with the experimental data (as shown in Fig. 10). The adsorption rate constants $k$ were $0.01 \times 10^{-3} \mathrm{~min}^{-1}$ and $0.02 \times 10^{-3} \mathrm{~min}^{-1}$. In a practical application, the Yoon-Nelson model is simpler than the other models because it does not consider the flow rate of the adsorbate and the adsorbent dosage. In addition, it can also obtain the time required to adsorb $50 \%$ of the adsorbent, so the adsorption efficiency can be compared.

When the initial concentration was $45 \mathrm{mg} / \mathrm{L}$, the contact time and the effluent concentration became larger until an equilibrium was reached. In the early stage of adsorption, when the LY dye passed through the stationary phase, the CSCF had enough adsorption sites to fully absorb the dye molecules, so the effluent concentration in the initial stage was relatively low. However, with the passage of the dye solution, the CSCF adsorbs dye molecules, the adsorption sites gradually decreased, and the adsorption gradually reached saturation. Finally, the stationary phase did not have the ability to adsorb, i.e., the effluent concentration was equal to the initial concentration of dye and reached equilibrium. The equilibrium time of the dynamic adsorption was $420 \mathrm{~min}$.

\section{Analysis of the Desorption and Secondary Adsorption}

With the increase in desorption time, the desorption rate increased from 5 min to 35 min (as shown in Fig. 11a). After $35 \mathrm{~min}$, the desorption reaction reached equilibrium and the highest desorption rate reached $98.183 \%$. Therefore, a $\mathrm{NaOH}$ solution has a good desorption effect on the CSCF adsorbent after saturated adsorption of LY dye. 

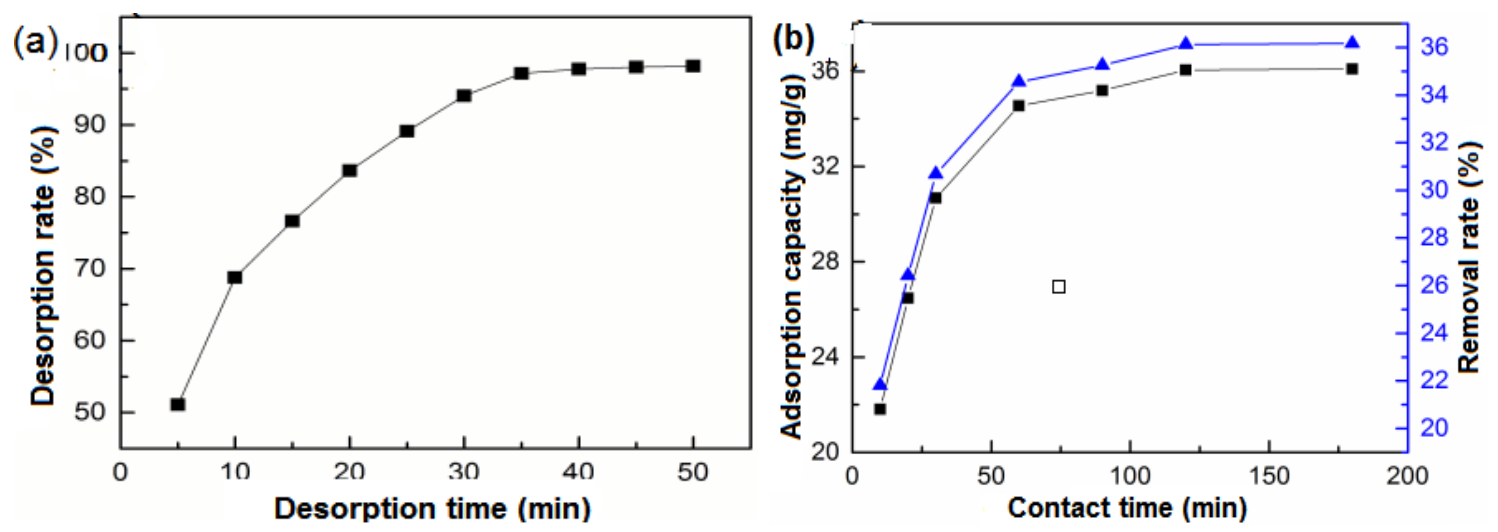

Fig. 11. The desorption and secondary adsorption

When the time was between $10 \mathrm{~min}$ and $120 \mathrm{~min}$, when the contact time increased, the adsorption capacity and removal rate increased (Fig. 11b). At $120 \mathrm{~min}$, the adsorption reaction gradually reached equilibrium. The highest adsorption capacity was $36.1 \mathrm{mg} / \mathrm{g}$, and the highest removal rate was $36.2 \%$. According to the experimental data, the CSCF after undergoing saturated adsorption for LY dye had a maximum adsorption capacity of $37.7 \mathrm{mg} / \mathrm{g}$ and a maximum removal percentage of $37.7 \%$. The experimental results shows that the adsorption capacity and removal extent of the CSCF secondary adsorption after the desorption were similar to those of the first adsorption. Therefore, the saturated CSCF adsorbent for LY dye still showed good adsorption performance after undergoing desorption.

\section{CONCLUSIONS}

1. A cationic straw cellulose fiber (CSCF) adsorbent was prepared via cationic modification with SCF. The optimal adsorption conditions of the CSCF for light yellow (LY) dye were as follows: a $\mathrm{pH}$ of 4 , a temperature of $30^{\circ} \mathrm{C}$, a CSCF dosage of 0.4 $\mathrm{g} / \mathrm{L}$, an initial concentration of $50 \mathrm{mg} / \mathrm{L}$, and a contact time between the CSCF and LY dye of $90 \mathrm{~min}$.

2. Results showed that the highest adsorption capacity was $137.6 \mathrm{mg} / \mathrm{g}$ and the highest removal percentage was $99.3 \%$. The pseudo-second-order kinetic model described the adsorption process well, and it also conformed to the Langmuir isotherm model. The thermodynamic model described that the adsorption reaction was spontaneous, and the adsorption process was an exothermic reaction.

3. Dynamic adsorption testing showed that the time to reach equilibrium was $420 \mathrm{~min}$ when the concentration of the LY dye solution was $45 \mathrm{mg} / \mathrm{L}$. The theoretical data calculated using the Yoon-Nelson model had a good fit with the experimental data. After desorption via a diluted $\mathrm{NaOH}$ solution, the maximum adsorption capacity was still $36.1 \mathrm{mg} / \mathrm{g}$ and the maximum removal rate still reached $36.2 \%$.

4. This work showed that CSCF was an efficient biosorbent for dye wastewater purification process. Its preparation and use provide a new method for the effective utilization of rice straw resources. 


\section{ACKNOWLEDGMENTS}

The authors are grateful for the support of the Fundamental Research Funds for the Central Universities, Grant No. 2572017CB08.

\section{REFERENCES CITED}

Alver, E., Bulut, M., Bulut, M., Metin A. U., and Ciftci, H. (2017). "One step effective removal of Congo Red in chitosan nanoparticles by encapsulation," Spectrochimica Acta Part A: Molecular and Biomolecular Spectroscopy 171(1), 132-138. DOI: 10.1016/j.saa.2016.07.046

Asfaram, A., Ghaedi, M., Hajati, S., Goudarzi, A., and Dil, E. A. (2017). "Screening and optimization of highly effective ultrasound-assisted simultaneous adsorption of cationic dyes onto $\mathrm{Mn}$-doped $\mathrm{Fe}_{3} \mathrm{O}_{4}$-nanoparticle-loaded activated carbon," Ultrasonics Sonochemistry 34(1), 1-12. DOI: 10.1016/j.ultsonch.2016.05.01

Baldikova, E., Safarikova, M., and Safarik, I. (2015). "Organic dyes removal using magnetically modified rye straw," Journal of Magnetism and Magnetic Materials 380(4), 181-185. DOI: 10.1016/j.jmmm.2014.09.003

Chen, K., Zhang, Z., Xia, K., Zhou, X., Guo, Y., and Huang, T. (2019). "Facile synthesis of thiol-functionalized magnetic activated carbon and application for the removal of mercury(II) from aqueous solution," ACS Omega 4(5), 8568-8579.

DOI: $10.1021 /$ acsomega.9b00572

Ciftci, D., Flores, R. A., and Saldaña, M. D. A. (2018). "Cellulose fiber isolation and characterization from sweet blue lupin hull and canola straw," Journal of Polymers and the Environment 26(7), 2773-2781. DOI: 10.1007/s10924-017-1164-5

De, D., Santosha, S., Aniya, V., Sreeramoju, A., and Satyavathi, B. (2018). “Assessing the applicability of an agro-industrial waste to engineered bio-char as a dynamic adsorbent for Fluoride Sorption," Journal of Environmental Chemical Engineering 6(2), 2998-3009. DOI: 10.1016/j.jece.2018.04.021

Elumalai, S., Agarwal, B., Runge, T. M., and Sangwan, R.S. (2016). "Integrated twostage chemically processing of rice straw cellulose to butyl levulinate," Carbohydrate Polymers 150(10), 286-298. DOI: 10.1016/j.carbpol.2016.04.122

Enniya, I., Rghioui, L., and Jourani. A. (2018). "Adsorption of hexavalent chromium in aqueous solution on activated carbon prepared from apple peels," Sustainable Chemistry and Pharmacy 7(3), 9-16. DOI: 10.1016/j.scp.2017.11.003

Fan, S., Wang, Y., Wang Z., Tang, J., and Li., X. (2017). "Removal of methylene blue from aqueous solution by sewage sludge-derived biochar: Adsorption kinetics, equilibrium, thermodynamics and mechanism," Journal of Environmental Chemical Engineering 5(1), 601-611. DOI: 10.1016/j.jece.2016.12.019

Freundlich, H. M. F. (1906). "Over the adsorption in solution," Journal of Physical Chemistry 57, 4574-4578.

Ge, Y., Wang, C., Liu, S., and Huang, Z. (2016). "Synthesis of citric acid functionalized magnetic graphene oxide coated corn straw for methylene blue adsorption," Bioresource Technology 221(12), 419-429. DOI: 10.1016/j.biortech.2016.09.060

Ghasemi, S. M., Ghaderpoori, M., Moradi, M., Taghavi, M., and Karimyan, K. (2020). "Application of Box-Behnken design for optimization of malachite green removal 
from aqueous solutions by modified barley straw," Global NEST Journal 22(3), 390399. DOI: $10.30955 /$ gni.003089

Halysh, V., Sevastyanova, O., Pikus, S., Dobele, G., Pasalskiy, B., Gun'ko, V. M., and Kartel, M. (2020). "Sugarcane bagasse and straw as low-cost lignocellulosic sorbents for the removal of dyes and metal ions from water," Cellulose 27(14), 8181-8197. DOI: 10.1007/s10570-020-03339-8

Heibati, B., Rodriguez-Couto, S., Al-Ghouti, M. A., Asif, M., Tyagi, I., Agarwal, S., and Gupta, V. K. (2015). "Kinetics and thermodynamics of enhanced adsorption of the dye AR 18 using activated carbons prepared from walnut and poplar woods," Journal of Molecular Liquids 208(9), 99-105. DOI: 10.1016/j.molliq.2015.03.057

Hosseini, S. A., Vossoughi, M., Mahmoodi, N. M., and Sadrzadeh M. (2018). "Efficient dye removal from aqueous solution by high-performance electrospun nanofibrous membranes through incorporation of $\mathrm{SiO}_{2}$ nanoparticles," Journal of Cleaner Production 183(5), 1197-1206. DOI: 10.1016/j.jclepro.2018.02.168

Hu, D., and Wang, L. (2016). "Adsorption of ciprofloxacin from aqueous solutions onto cationic and anionic flax noil cellulose," Desalination and Water Treatment 57(58), 28436-28449. DOI: 10.1080/19443994.2016.1183232

Hu, L., Zang, L., Liu Q., Qiu, J., Yang, C., Xu, X., Yang, J., and Qiao, X. (2019). "Effective and selective removal of cationic dye from aqueous solution using rosin derivative modified wheat straw," Desalination and Water Treatment 153(6), 349356. DOI: $10.5004 / \mathrm{dwt} .2019 .24006$

Hubbe, M. A., Azizian, S., and Douven, S. (2019). "Implications of apparent pseudosecond-order adsorption kinetics onto cellulosic materials. A review," BioResources 14(3), 7582-7626. DOI: 10.15376/biores.14.3.7582-7626

Langmuir, I. (1916). "The constitution and fundamental properties of solids and liquids: Part I. Solids," Journal of the American Chemical Society 38(11), 2221-2295. DOI: $10.1021 / \mathrm{ja} 02268 \mathrm{a} 002$

$\mathrm{Li}, \mathrm{X}$., and Li, Y. (2019). "Adsorptive removal of dyes from aqueous solution by $\mathrm{KMnO}_{4}$-modified rice husk and rice straw," Journal of Chemistry 2019(8), 1-9. DOI: $10.1155 / 2019 / 8359491$

Lima, D. R., Sellaoui L., Klein, L., Reis, G. S., Lima, É. C., and Dotto, G. L. (2018). "Physicochemical and thermodynamic study of malachite green adsorption on raw and modified corn straw," Canadian Journal of Chemical Engineering 96(3), 779787. DOI: $10.1002 /$ cjce. 22948

Patil, P. R., Marathe, Y. V., and Shrivastava, V. S. (2015). "Evaluation of the adsorption kinetics and equilibrium for the potential removal of Congo red dye from aqueous medium by using a biosorbent," British Journal of Applied Science \& Technology 6(6), 557-573. DOI: 10.9734/BJAST/2015/12590

Sudhan, N., Subramani, K., Karnan, M., IIayaraja, N., and Sathish, M. (2016). "Biomassderived activated porous carbon from rice straw for high energy symmetric supercapacitor in aqueous and non-aqueous electrolytes," Energy \& Fuels 31(1), 977985. DOI: 10.1021/acs.energyfuels.6b01829

Sun, Y., Wu Z.-Y., Wang, X., Ding, C., Cheng, C., Yu, S.-H., and Wang, X. (2016). "Macroscopic and microscopic investigation of $\mathrm{U}(\mathrm{VI})$ and $\mathrm{Eu}(\mathrm{III})$ adsorption on bacterium-derived carbon nanofibers," Environmental Science \& Technology 53(19), 4459-4467. DOI: 10.1021/acs.est.9b04434

Xia T., Wang Y., and Fan, P. (2013). "Study on adsorption of modified rice hull for methylene blue simulated wastewater," Industrial Water Treatment 33(3), 47-50. 
Xie, M., Xiong F. P., Feng, C. L., Han, J. J. and Wu, X. (2019). "Preparation of cellulosegraphene oxide composite and its adsorption for $\mathrm{Pb}^{2+}$," Technology of Water Treatment 45(8), 67-70.

Zazycki, M. A., Godinho, M., Perondi, D., Foletto, E. L., Collazzo, G. C., and Dotto, G. L. (2017). "New biochar from pecan nutshells as an alternative adsorbent for removing reactive red 141 from aqueous solutions," Journal of Cleaner Production 171(1), 57-65. DOI: 10.1016/j.jclepro.2017.10.007

Zhang, X., Jin, C., Jiang, Y., Liu, G., Wu, G., and Kong, Z. W. (2017). “A novel gallic acid-grafted-lignin biosorbent for the selective removal of lead ions from aqueous solutions," BioResources 12(3), 5343-5357. DOI: 10.15376/biores.12.3.5343-5357

Zhu, L., Shen, F., Smith, R. L., Yan, L., Li, L., and Qi, X. (2017). "Black liquor-derived porous carbons from rice straw for high-performance supercapacitors," Chemical Engineering Journal 316(5), 770-777. DOI: 10.1016/j.cej.2017.02.034

Article submitted: February 21, 2021; Peer review completed: March 28, 2021; Revised version received and accepted: April 7, 2021; Published: April 20, 2021.

DOI: 10.15376/biores.16.2.3991-4006 